explained in any of the usual ways, a condition which has been pointed out by Tuckett (British Journal of Ophthalmology, February, 1918.)

\title{
SIDEROSIS BULBI
}

\author{
BY \\ F. H. VERHOEFF, \\ Boston, MASSACHUSETTS.
}

In the BRITISH JouRnal of OpHTHALMOLOGY for February there appeared a communication by Ivor Ll. Tuckett, M.D., on "Siderosis Bulbi," in which the author concludes that iron salts have a selective action on the nerve terminals in the dilatator and constrictor muscles of the iris. This conclusion is based on the fact that in the case reported the pupillary reactions became abolished, and were later restored after removal of the foreign body.

About thirteen years ago I made the observation that the cells of the dilatator, and, to a less extent, those of the constrictor muscle also, become densely packed with iron pigment in cases of siderosis bulbi, more so, in fact, than any other cells in the iris. This observation I have confirmed many times since, and in a discussion before the American Ophthalmological Society in 1906, I made brief mention of the fact that the dilatator muscle has a marked affinity for iron. The accompanying photograph strikingly illustrates this fact. It is of a section stained in haematoxylin and eosin, in which all of the natural pigment has been bleached by a modification of Alfieri's method.* Why such an evident condition has been overlooked by other observers is difficult to understand. From my observations, therefore, it would seem that the impaired motility of the iris in siderosis bulbi is not due to selective action on nerve terminals, but to impairment in function of the muscles of the iris resulting from their affinity for iron. In advanced cases of siderosis, chronic iritis is set up, which no doubt also impairs the motility of the iris.

The ciliary muscle, I find, becomes pigmented only in the immediate vicinity of the ligamentum pectinatum. This may be due to the fact that fluid containing iron does not reach it elsewhere, or to the fact that owing to its different origin it has less affinity for iron than the iris muscles.

The author of the communication referred to seems to be under a misapprehension in regard to the pigmentation of the lens that occurs in siderosis bulbi, he assuming that in his case the siderotic

"VERHOFFF and Fisher.-An improved method of bleaching pigmented tissues.Arch. of Ophthal., 1908, p. 561 . 


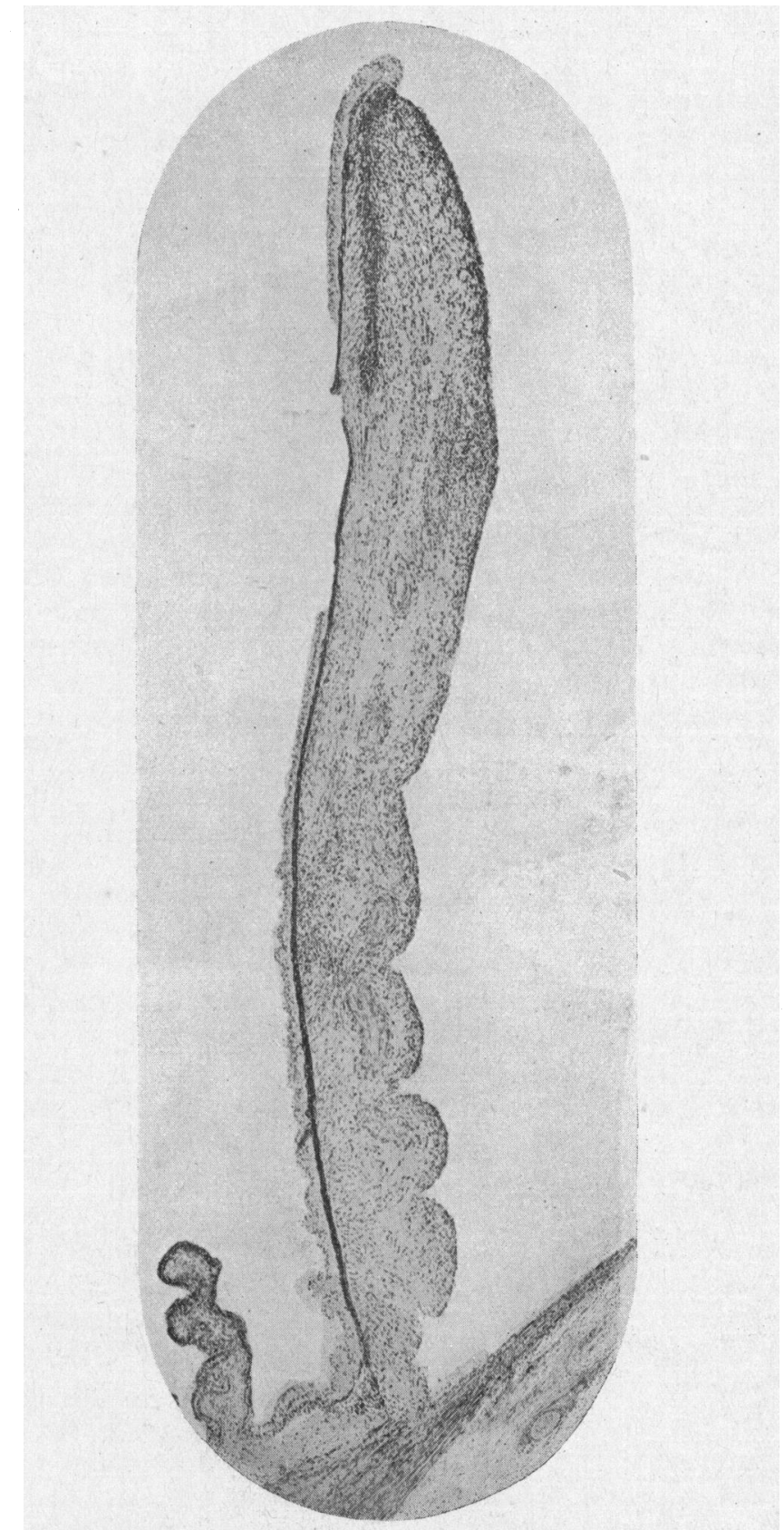

Intense pigmentation of the dilatator muscle of the iris in a case of siderosis bulbi. The natural pigment of the iris has been completely bleached so that the dilatator is plainly seen as a black line. The constrictor muscle is also pigmented, but this is not obvious in the photograph. 
particles were deposited on the front of the lens capsule. It is, of course, well established that the deposits occur neither upon nor within the capsule proper, but immediately behind it in the capsular epithelium. Here they tend to form two circles, one corresponding in position to the pupillary margin and the other occurring further out, but it is seldom that either of the circles is well defined.

\section{ANNOTATIONS}

\section{Optical Glass}

Among the many key industries that in pre-war days we weakly allowed to pass into German hands must be included optical glass employed in the manufacture of field glasses, telescopes, and firecontrol instruments. It will be recalled that in the earlier part of the war we were hard put to it to provide the necessary optical help to allow our officers to see properly at the front and that the deficiency was in part remedied by Lord Roberts's far-flung appeal for gifts of binoculars from those who happened to possess them.

Since then great strides have been taken in the making of optical glass, as anybody could convince himself by a visit to the recent British Scientific Products Exhibition, at King's College, London. Thanks largely to Sir Herbert Jackson, K.B.E., professor of chemistry at King's College, there has been an awakening of the glass industry, and we need never again go to Germany for optical glass. Meanwhile the American Journal of Ophthalmology, July, 1918, tells us how the situation has been met in the United States. In 1917, when that country entered upon the war, the optical glass situation was critical. Such glass was then made by four firms only, and the European supply was practically cut off. The geophysical laboratory of the Carnegie Institution of Washington was called upon, and a party of scientific men was detached from the laboratory and stationed at the plant of one of the manufacturing firms. At the end of several months essential details of the manufacture had been developed and glass in considerable quantities was being produced. The knowledge gained by the laboratory was then extended to other firms, with the result that at the present time large quantities of optical glass of the kinds needed for military fire-control instruments are being produced, and of a quality equal in every respect to the best European glass. 